\title{
Gastrointestinal Hamartoma
}

National Cancer Institute

\section{Source}

National Cancer Institute. Gastrointestinal Hamartoma. NCI Thesaurus. Code C96475.

A non-neoplastic, hamartomatous polyp that arises from the stomach, small intestine, and large intestine. This group includes the juvenile polyps and Peutz-Jeghers polyps. 